\title{
SYNOVIAL SARCOMA AT AN UNUSUAL LOCATION- SCROTUM
}

\section{P. Madhu', Swetha Venugopal}

1 Professor and HOD, Department of General Surgery, JSS University. 2Junior Resident, Department of General Surgery, JSS University.

HOW TO CITE THIS ARTICLE: Madhu CP, Venugopal S. Synovial sarcoma at an unusual location- scrotum. J. Evolution Med. Dent. Sci. 2017;6(54):4113-4114, DOI: 10.14260/Jemds/2017/889

\section{PRESENTATION OF CASE}

A case of a 28-year-old male who had complaints of swelling in the right inguinoscrotal region for 6 months, which was initially small in size in the scrotum and increased in size to the present size of $12 * 6 \mathrm{~cm}$ extending to the inguinal region. Swelling was painless, gradually progressive, firm in consistency. Patient had history of right hernioplasty one year back.

\section{Local Examination}

Swelling measuring $12 * 6 \mathrm{~cm}$ in the right scrotal region extending to the inguinal region, skin above the swelling was normal. Scar of $4 \mathrm{~cm}$ was present in right inguinal region. No cough impulse.

\section{Palpation}

No local rise of temperature, non-tender, firm in consistency.

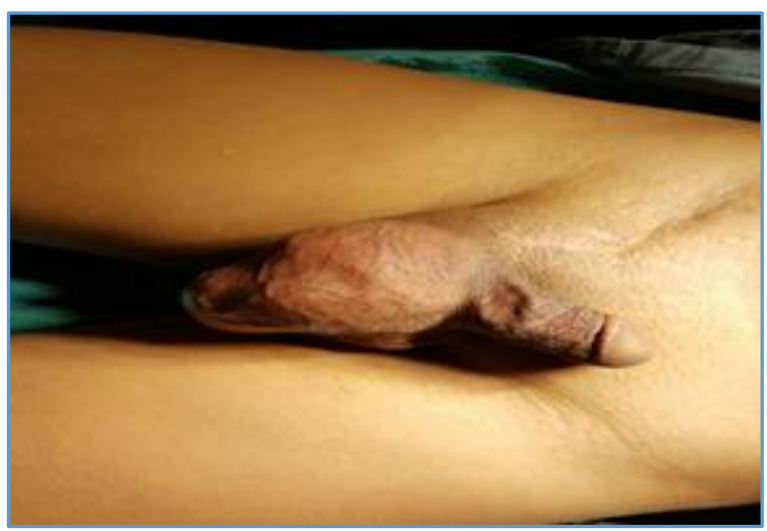

Figure 1

Patient was investigated as follows- FNAC- features s/o spindle cell tumour MRI: Large well-defined lobulated enhancing soft tissue lesion in the right scrotal neck region with suspicious involvement of corpus spongiosumneoplastic origin.

Patient underwent wide local excision with high inguinal orchidectomy.

Financial or Other, Competing Interest: None.

Submission 27-03-2017, Peer Review 21-06-2017,

Acceptance 29-06-2017, Published 06-07-2017.

Corresponding Author:

Dr. Swetha Venugopal,

No. 29/30 Horamavu,

Behind SBM $2^{\text {nd }}$ Main,

Bangalore- 560043.

E-mail: venugopalswetha99@gmail.com

DOI: $10.14260 /$ jemds $/ 2017 / 889$

\section{(c) (i) $(\mathrm{S})$}

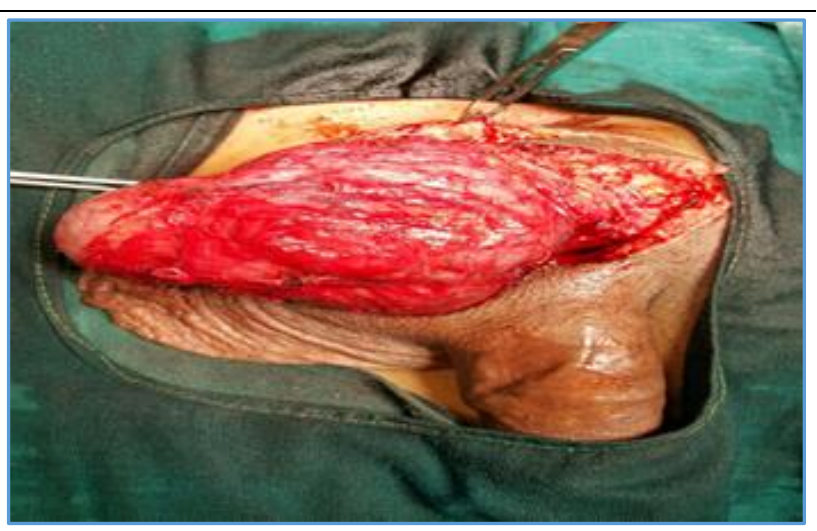

Figure 2. Intraop Photo showing Complete Excision of the Swelling

\section{DIFFERENTIAL DIAGNOSIS}

A Synovial Sarcoma (SS) is an aggressive soft tissue tumour, which mainly occurs in the para-articular region of extremities with a predilection of lower limb. Synovial Sarcoma (SS) though rare is a morphologically, clinically and genetically distinct entity. With the advent of immunohistochemistry and molecular techniques, cases of synovial sarcomas have been reported in an unusual location including the head and neck, mediastinum, lung, abdominal wall, intra-abdominal, kidney and retroperitoneum.1,2 Although, SS is named because of the histological resemblance to the synovium, joints are rarely involved and the origin has been attributed to pluripotent mesenchymal cells.[1] The monophasic SS consisting solely of sarcomatous components is often diagnostically challenging. The differential diagnosis depends on the type of SS. Careful attention to histopathological features, high degree of suspicion and a battery of IHC markers allow us to exclude the wide range of tumours in the differential and arrive at the correct diagnosis. ${ }^{3}$ Careful attention to histopathological features, high degree of suspicion and a battery of IHC markers allow us to exclude the wide range of tumours in the differential and arrive at the correct diagnosis.

\section{CLINICAL DIAGNOSIS}

A clinical case of a patient with an asymptomatic inguinoscrotal swelling diagnosed as a synovial sarcoma is presented.

\section{DISCUSSION OF MANAGEMENT}

Synovial sarcomas are uncommon soft tissue tumours accounting for $5-10 \%$ of the soft tissue sarcomas. They usually develop in children and young adults and approximately $95 \%$ of SSs occur in the extremities. They can metastasize distantly, especially to the lung and lymph. Despite its name, synovial sarcoma is not related to the synovial tissues that are a part of the joints. The disease starts 
most commonly in the legs or arms, but it can appear in any part of the body. 4

Two major histologic subtypes exist: monophasic and biphasic synovial sarcomas. The classical SS has a biphasic appearance with a mixture of epithelial and spindle cells in varying proportions. The monophasic SS consisting solely of sarcomatous components is often diagnostically challenging.

A correct initial histopathologic diagnosis of monophasic SS is often difficult: the differential diagnosis including other spindle-cell tumours such as malignant peripheral nerve sheath tumours, leiomyosarcoma, rhabdomyosarcoma, fibrosarcoma, solitary fibrous tumour and spindle cell carcinoma. Biphasic SS is easier to identify with malignant peripheral nerve sheath tumours, carcinosarcoma and malignant mesothelioma being the differential diagnosis.5,6

There are no well-established risk factors for synovial sarcoma, but the disease is associated with the chromosomal translocation $t(X ; 18)$ (p11;q11). Most (90\%) SS exhibit a translocation $\mathrm{t}(\mathrm{X} ; 18)(\mathrm{p} 11: \mathrm{q} 11)$ between chromosomes 18 (SYT gene) and X (SSX gene) resulting in a SYT-SSX-1 (biphasic SS) or SYT-SSX-2 (monophasic SS) fusion.7 Generally, we use break-apart FISH and RT-PCR to search the translocation. This translocation is specific and diagnostic for SS. $5,6,8$

A slow growing painless mass is common and may give the false impression that it is harmless. When a tumour is painless and deep-seated within the body, it may go unnoticed for a long time. Because tumours can go unnoticed, followup guidelines generally involve regular imaging (such as CT scans) after treatment is completed. These tests can detect recurrences at the site of the original tumour or elsewhere in the body.

Less than $10 \%$ of patients have detectable metastases at the time of diagnosis. In such cases, synovial sarcoma tumour cells are believed to have moved from one site (origin) to the second site (metastatic). The lungs are the most common location for metastases as mentioned above.

Preoperative diagnosis of SS is challenging because of its nonspecific symptomatology, low clinical morbidity, lack of specific radiologic features and physician's unfamiliarity. The most frequent preoperative diagnosis is neurogenic tumours and a recent study of peripheral SS suggests that pain, short symptom duration, peritumoural oedema without a definite target sign on MR images should evoke SS. ${ }^{9}$

Prognosis of synovial sarcoma has been related to tumour size, ${ }^{10,11}$ biphasic histology, 7,10,11 SSY-SSX2 gene fusion and negative resection margins. ${ }^{1}$ Surgery is the mainstay of treatment. Chemotherapy and radiation therapy should be considered as additional treatment options or may be utilised in cases of relapse. Radiation seems to confer a local control and survival benefit, while the role of chemotherapy is controversial. ${ }^{10}$ Prognosis is poor with local recurrence and metastases in almost $50 \%$ cases.

\section{FINAL DIAGNOSIS}

Synovial sarcoma is an extremely rare head and neck malignancy. Monophasic synovial sarcoma in an unusual location can present as a diagnostic dilemma.

\section{REFERENCES}

[1] Adam YG, Oland J, Halevy A, et al. Primary retroperitoneal soft-tissue sarcomas. Journal of Surgical Oncology 1984;25(1):8-11.

[2] Clark J, Rocques PJ, Crew AJ, et al. Identification of novel genes, SYT and SSX, involved in the $t(X: 18)$ (p11.2; q11.2) translocation found in human synovial sarcoma. Nat Genet 1994;7(4):502-8.

[3] Mills SE, Carter D, Greenson JK, et al. Disorders of soft tissues. Sternberg's Diagnostic Surgical Pathology 2004;4:193-4.

[4] Fetsch JF, Meis JM. Synovial sarcoma of the abdominal wall. Cancer 1993;72(2):469-77.

[5] Weiss SW, Goldblum JR. Synovial sarcoma synovial sarcoma. $5^{\text {th }}$ edn. In: Weiss SW, Goldblum JR. (eds). Enzinger and Weiss's soft tissue tumors. St Louis: Mosby, 2008:1161-82.

[6] Lindberg MR. Diagnostic pathology: soft tissue tumors. Health Sciences: Elsevier, 2015.

[7] Guillou L, Benhattar J, Bonichon F, et al. Histologic grade, but not SYT-SSX fusion type, is an important prognostic factor in patients with synovial sarcoma: a multicenter, retrospective analysis. J Clin Oncol 2004;22(20):4040-50.

[8] Fletcher DM, Unni KK, Mertens F. WHO classification of tumors pathology and genetics of tumurs of soft tissue and bone. Lyon: IARC Press, 2002.

[9] Kang S, Yoo HJ, Kim HS, et al. Soft tissue sarcoma misdiagnosed as benign peripheral neurogenic tumor. J Orthop Sci 2015;20(1):180-5.

[10] Harb WJ, Luna MA, Patel SR, et al. Survival in patients with synovial sarcoma of the head and neck: association with tumor location, size, and extension. Head Neck 2007;29(8):731-40.

[11] Wushou A, Miao XC. Tumor size predicts prognosis of head and neck synovial cell sarcoma. Oncol Lett 2015;9(1):381-6. 